\title{
O PROBLEMA DA DEMARCAÇÃO CIENTÍFICA EM KARL POPPER
}

\author{
Juliana Barbosa Brito ${ }^{1}$
}

RESUMO: A preocupação em identificar características próprias da ciência é algo recorrente ao longo da história da filosofia. Muitos critérios de demarcação científica já foram propostos sob diversos pontos de vista. Tal problema foi investigado pelo filósofo Karl Popper ao constatar a necessidade de um critério adequado que determinasse o caráter científico de uma teoria. No presente artigo pretendo apresentar o problema da demarcação entre conhecimento científico e conhecimento não científico no pensamento epistemológico de Karl Popper. Abordarei a crítica do filósofo ao método indutivo de pesquisa, bem como a crítica dirigida à filosofia positivista do Círculo de Viena, demonstrando que o método positivista de verificação, proposto como critério de demarcação, não é plausível para determinar o caráter científico de uma teoria. Por fim, apresentarei o método de investigação científica defendido por Popper, e a sua solução para o problema da demarcação.

PALAVRAS-CHAVE: Epistemologia; Indução; Demarcação Científica; Falseabilidade. 


\begin{abstract}
The concern to identify typical characteristics of science is something recurrent throughout the history of philosophy. Many scientific demarcation criteria have already been proposed under various points of view. Such a problem was investigated by the philosopher Karl Popper in order to seek for an adequate criterion in determining the character of a scientific theory. In this article I intend to present the problem of demarcation between scientific and non-scientific knowledge on the epistemological thought of Karl Popper. I'll discuss the critics of the philosopher to the inductive method of research, as well as the criticism addressed to the positivist philosophy of the Vienna Circle, demonstrating that the positivist verification method, proposed as a demarcation criterion, it is not feasible to determine the character of a scientific theory. Finally, I will present the scientific research method carried out by Popper, and his solution for the problem of demarcation.
\end{abstract}

KEYWORDS: Epistemology; Induction; Demarcation Problem; Falsifiability. 
A filosofia de Karl Raimund Popper (1902-1994) está presente no cerne do pensamento epistemológico do século XX. Sua obra abarca questões fundamentais da filosofia da ciência, tal como o método científico, o problema da verdade e da racionalidade. Surge com o filósofo o que ele denomina "racionalismo crítico", uma nova forma de lidar com a ciência, onde a jornada em busca da verdade é guiada sempre por posicionamentos críticos e racionais.

O presente trabalho pretende investigar o problema da demarcação científica em Karl Popper. O objetivo é esclarecer as razões que levaram o filósofo a se ocupar desse problema em grande parte da sua obra e apontar a sua solução dada para o mesmo. Razões essas que estavam relacionadas a algumas teses filosóficas anteriores e até mesmo contemporânea ao filósofo, a saber: o problema da indução e a filosofia positivista do Círculo de Viena.

\section{O PROBLEMA DA INDUÇAO}

A indução consiste em construir um discurso da ciência a partir de fatos observados (experiência). Esse tipo de raciocínio pretende anunciar leis universais baseadas em alguns fatos observados, ou seja, a partir de certo número de observações, chega-se a uma conclusão generalizada. Essa passagem do particular para o universal é o que chamamos de indução. Por exemplo: se experienciamos 10 vezes que a pele queima em contato com o fogo, concluiremos que o fogo é um fenômeno que queima a pele. Percebe-se que o conhecimento passou de alguns fatos isolados para uma conclusão mais geral, esse alargamento 
do conhecimento é em que consiste o raciocínio indutivo.

O problema da indução foi uma das grandes preocupações de Popper, pois:

"a indução foi sempre um dos critérios mais populares para a demarcação do campo da ciência, as ciências empíricas são, via de regra, caracterizadas pelos seus métodos, os quais, por sua vez, são geralmente qualificados de indutivos".

O que inquietava Popper era a incoerência desse método e do seu critério de demarcação científica, que veio a ser apontada primeiramente por Hume. David Hume foi quem, pela primeira vez na história da filosofia, levantou questões relativas ao método indutivo e às suas falhas. O problema da indução, ou o problema de Hume (como é comumente nomeado) foi considerado por Popper como um dos mais importantes problemas do século passado e foi através de Hume que Popper chegou a tal discussão. O empirista escocês notou que não era possível justificar por meio da lógica o método indutivo porque não temos razão para sustentar leis gerais partindo de fatos observados para fatos não observados. Ou seja, não há como justificar logicamente uma conclusão da qual ainda não tivemos experiência, baseada apenas em observações passadas, desmerecendo os acontecimentos e descobertas futuras. E nem se apoiando na experiência, pois, de acordo com Popper:

A tentativa de justificar a prática da indução por um apelo à experiência tem de conduzir a uma regressão infinita. Em consequência, podemos dizer que as teorias nunca podem ser inferidas de enunciados de observação, ou racionalmente justificadas por eles. ${ }^{3}$ 
O método de raciocínio que parte de enunciados particulares para leis universais com pretensão de verdade, não se justifica pelo fato de que as afirmações baseadas na experiência falam sobre o singular e não sobre o universal. ${ }^{4}$

A resposta de Hume ao problema da indução é baseada na ideia de costume ou hábito, para ele "somos condicionados pelas repetições e pelo mecanismo de associação de ideias, mecanismo sem o qual, diz Hume, dificilmente poderíamos sobreviver"5. Para Popper a resposta ao problema da indução oferecida por Hume é irracionalista, pois está baseada na crença humana e na necessidade de regularidade do universo. Em termos filosóficos é uma explicação insuficiente, uma tentativa malograda, que mais parecia uma teoria psicológica. Os seres humanos acreditam que há certa regularidade nas coisas, no que se refere aos fenômenos, por isso tendemos a acreditar que o futuro será igual ao passado, é o que defende Hume. Popper afirma que tal teoria nos leva a conclusão de que a razão desempenha um papel menor no entendimento.

O problema da indução pode ser analisado através de dois pontos de vista distintos: o lógico e o psicológico. O problema lógico da indução consiste no fato de que não podemos justificar o método indutivo, pois não há argumento lógico válido que nos permita afirmar que aqueles casos dos quais não tivemos experiência alguma se assemelham àqueles que já experimentamos anteriormente. A falta de resposta ao problema lógico da indução nos conduz ao seu problema psicológico. O problema psicológico da indução consiste na tese humeana de que "o costume ou o hábito" é o guia que nos leva ao conhecimento. Possuímos uma crença quase instintiva na continuidade dos acontecimentos passados em relação ao futuro. A teoria psicológica de Hume nada 
mais é do que parte do senso-comum, uma explicação popular e que pode e deve ser refutada logicamente. Mesmo Hume admitindo que a indução é um método logicamente inválido, ele não foi razoável em propor uma explicação psicológica da indução, deixando em segundo plano o papel da razão. E foi essa explicação psicológica que manteve Hume no plano irracional no que tange ao conhecimento científico.

Não há duvida de que Hume tinha mais em vista uma teoria psicológica do que propriamente filosófica, pois tentou dar uma explicação causal de um fato psicológico - o fato de acreditarmos em leis, enunciados que afirmam padrões de regularidades ou tipos de acontecimentos constantemente associados. $^{6}$

Popper concorda plenamente com Hume em relação à não justificação lógica da indução, mas discorda da explicação psicológica da indução em termos de costume ou hábito. Neste sentido é que Popper defende que a via da indução deve ser evitada porque ela nos conduz ao irracionalismo. Mas Popper diz solucionar o problema de Hume, e ainda alega que “... não há choque entre minha teoria de não-indução e a racionalidade, ou o empirismo, ou o procedimento da ciência". ${ }^{7}$

Se para Popper não é razoável alegarmos que uma lei universal, que tenha sido extraída de observações particulares, seja verdadeira, porque nenhuma quantidade de enunciados particulares verdadeiros justificaria a conclusão de uma asserção universal verdadeira, é racionalmente correto alegar a falsidade de uma lei universal baseado no valor de verdade das asserções particulares (testadas). E assim Popper conclui: "não há, pois, indução: nunca argumentamos passando de fatos para teorias - a 
não ser com o objetivo de refutar ou falsear as teorias".

O que Popper defende é uma postura crítica e racionalista nas ciências, que se caracteriza pela tentativa de refutar racionalmente as teorias a fim de eliminar os erros e com isso possibilitar a ciência caminhar em direção ao progresso. Para ele, não se pode produzir conhecimento pelo método indutivo, ao contrário, é pelo método dedutivo que essa produção é possível, mesmo sendo um conhecimento de natureza conjectural.

Embora os dois referidos problemas (indução e demarcação) tivessem origem na modernidade, são investigados por Popper em sua obra A Lógica da Pesquisa Científica como uma discussão crítica à doutrina positivista do Círculo de Viena. Apesar de ter vivenciado o mesmo momento histórico e filosófico dos positivistas lógicos, Popper adotou uma postura avessa a estes e assim conquistou um lugar diferenciado na história da filosofia contemporânea.

$\mathrm{O}$ conceito de ciência vigente em seu meio intelectual era o conceito postulado pelo positivismo lógico do Círculo de Viena. Esses filósofos defendiam o emprego do método indutivo nas ciências empíricas, cuja característica principal, como já foi dito, é a obtenção de leis gerais a partir de enunciados singulares. Porém, o método indutivo é inadmissível, pois

[...] com efeito, qualquer conclusão colhida desse modo sempre pode revelar-se falsa: independente de quantos casos de cisnes brancos possamos observar, isso não justifica a conclusão de que todos os cisnes são brancos. ${ }^{9}$

Popper argumenta que o problema da indução está intrinsecamente relacionado ao problema da demarcação, e uma das razões de ele rejeitar o critério de demarcação defendido 
pelo Círculo de Viena é justamente por ele ser pautado na lógica indutiva.

\section{O PROBLEMA DA DEMARCAÇÃO}

A lógica indutiva dos positivistas vienenses não apresentava, na visão de Popper, um adequado critério de demarcação. Os positivistas admitiam como científicas apenas aquelas ideias que fossem fruto da experiência. Deste modo, a metafísica, por exemplo, é considerada pelos positivistas sem sentido, portanto, não científica, por não ser justificada empiricamente. Segundo Popper:

Os positivistas normalmente interpretam o problema da demarcação de maneira naturalista; interpretam-no como se ele fosse um problema da ciência natural. Em vez de torná-lo como razão que os leve a empenhar-se em propor uma convenção adequada, acreditam estar obrigados a descobrir uma diferença decorrente da natureza das coisas, por assim dizer, entre ciência empírica, de um lado, e metafísica de outro. Estão constantemente procurando mostrar que a metafísica, por sua própria natureza, nada mais é que tagarelice vazia - "ilusão", como diz Hume, que devemos lançar ao fogo. ${ }^{10}$

Popper não estava preocupado com o sentido, o significado ou a validade de um sistema, tampouco pretendia aniquilar a metafísica, como os positivistas vienenses pretendiam. Se uma teoria é considerada não científica ou metafísica, não implica dizer que é destituída de sentido ou significado, significa apenas 
que "não pode ser apoiada por provas empíricas em sentido científico"11. Popper queria demonstrar, que o seu critério de demarcação entre ciência e metafísica não era o mesmo da demarcação entre sentido e sem sentido.

Os positivistas não se contentavam em dizer apenas que a metafísica não pertencia à ciência empírica, as expressões "sem sentido" ou "vazia" foram usadas por eles em caráter depreciativo, e o que os positivistas queriam de fato não é demarcar o lugar da ciência e o da metafísica, mas sim destruir esta última. Este é um dos motivos que faz Popper acreditar que os positivistas estavam equivocados com o seu critério de demarcação, pois mesmo que a metafísica não seja ciência, não implica dizer que é desprovida de sentido.

"Toda vez que os positivistas tentaram esclarecer melhor o que pretendiam dizer com "significativo", a tentativa conduziu ao mesmo resultado - a uma definição de "sentença significativa" (em contraposição a "pseudosentença, sem significado") que simplesmente reiterou o critério de demarcação de sua Logica Indutiva."12

Aqui Popper dirige a sua critica diretamente a Wittgenstein, cuja filosofia foi a inspiração principal dos teóricos do Círculo de Viena. Wittgenstein, em sua obra Tractatus Logico-Philosophicus, de 1922, versa sobre problemas de caráter lógico e ético sob o uso de aforismos. O objetivo principal da obra era expressar a relação lógica existente entre pensamento, linguagem e mundo. Wittgenstein, assim como outros filósofos de orientação lógicocientífica, acredita que "grande parte dos problemas científicos e filosóficos só poderão ser resolvidos através da análise lógica da linguagem"13. Para Wittgenstein, existe uma correspondência 
rigorosa entre o mundo e a linguagem, sendo a linguagem aquilo que figura o mundo, e este, citando o aforismo do próprio filósofo, "é a totalidade dos fatos, não das coisas"14. É importante aqui esclarecer a estrutura do mundo e da linguagem, para que possamos compreender a sua teoria da figuração do mundo. A definição de mundo, como sendo a totalidade dos fatos e não das coisas, nos permite fazer uma distinção entre fatos e coisas. "A totalidade dos fatos determina, pois, o que ocorre e também tudo o que não ocorre"15, logo, os fatos são, no espaço lógico, o mundo. E tudo o que ocorre é o subsistir dos estados das coisas, e este é uma vinculação de objetos. A diferença entre ambos é "que o estado de coisas se refere unicamente ao conteúdo descritivo das frases, enquanto fato se refere a sua realidade" 16 .A linguagem, por sua vez, constitui a totalidade das proposições, sendo a proposição aquilo que figura a realidade, ela é o modelo da realidade tal qual pensamos. Nota-se, portanto, que há uma correspondência lógica entre realidade e linguagem.

A teoria da figuração do mundo representa a preocupação de Wittgenstein em analisar e compreender a correspondência entre o mundo e a linguagem, e para ele só é possível essa correspondência quando ambos - mundo e linguagem - possuem um ponto em comum, que ele chamará de forma de afiguração: "O que a figuração deve ter em comum com a realidade para poder afigurar à sua maneira - correta ou falsamente - é a sua forma de afiguração" ${ }^{17}$. Se forma de afiguração é a "forma lógica", logo toda figuração é também lógica. Isso quer dizer que para que haja essa correspondência, o mundo dos fatos e o mundo do pensamento (linguagem) devem possuir uma identidade estrutural, ou seja, a estrutura de um corresponde à estrutura do outro. Nasce daí, portanto, a questão da verdade, no sentido de 
que a verdade "nada mais é do que a identidade das estruturas das coisas e do pensamento." ${ }^{18}$ A verdade ou falsidade da figuração está expressa no aforismo 2.222 do Tractatus: "Na concordância ou na discordância de seu sentido com a realidade consiste sua verdade ou falsidade."

Para Wittgenstein toda proposição deve ser significativa, ou possuir algum sentido, que é atestado quando ela diz algo acerca do mundo. $\mathrm{O}$ valor de verdade da proposição está na comparação com o mundo, e essa comparação se dá a partir da observação (experiência). Desta forma, as proposições filosóficas (ou metafísicas) não são consideradas como significativas pois não possibilitam a comparação com o mundo real, através da observação.

O critério de demarcação popperiano foi elaborado pelo filósofo como uma crítica ao critério da significação de Wittgenstein, que ele o considera como um pseudo-problema, já que para ele se trata apenas de um problema verbal. Este critério defende a tese de que toda proposição genuína tem de ser uma função de verdade dedutível de enunciados de observação. Popper aponta para a equivalência entre o critério da verificabilidade defendida pelos positivistas e o critério de significação de Wittgenstein, contanto apenas que substituía os termos "científico" por "significativo". O positivismo lógico do Círculo de Viena utiliza o critério da verificação, segundo o qual todas as teorias científicas têm de ser empiricamente observáveis, isto é, o seu valor de verdade é estabelecido através da observação empírica. Porém, Popper discorda dos filósofos positivistas, pois segundo ele nenhuma teoria científica, ou lei universal, pode ser obtida de afirmações derivadas somente da observação. A teoria poderá, no entanto, ser falseada pela observação no momento em 
que esta contradiz aquela. Popper esclarece:

Este fato torna possível inferir de observações que uma teoria é falsa. A possibilidade de refutar teorias por meio de observações constitui a base de toda experimentação empírica. Com efeito, o teste de uma teoria é sempre, e à semelhança de qualquer exame rigoroso, uma tentativa de demonstrar que o candidato está enganado - ou seja, que a teoria implica uma asserção falsa. De um ponto de vista lógico, todos os testes empíricos, serão, nessa medida, tentativas de refutação.19.

O critério de demarcação da lógica indutiva diz respeito à verdade ou a falsidade dos enunciados "verificados pela experiência”. Essa validez está relacionada, como citado anteriormente, ao "dogma positivista de significado". Enunciados que não podem ser verificados empiricamente são desse modo, destituídos de significado.

Popper sempre ressaltou que o seu critério não é de significação, e que alias, esse é o principal ponto que separa o seu pensamento do pensamento positivista. Popper jamais esteve preocupado em fazer análise lógica de enunciados, como os analíticos do Círculo, o seu critério de demarcação é aplicado com o objetivo de distinguir os sistemas teóricos dos sistemas empíricos.

Contrário ao positivismo, Popper não desconsidera a metafísica, para ele a metafísica tem o seu lugar diante do fazer ciência. Defende que existem ideias metafísicas que favorecem o avanço da ciência (tais comoas relativasao atomismo especulativo). E que o cientista muitas vezes possui uma fé destituída de base perante as descobertas científicas, e as ideias especulativas que daí surgem pode ser, em certa medida, metafísicas. 
Com efeito, ao rejeitar o critério positivista de demarcação, Popper enfatiza que não se pode verificar empiricamente as teorias que são fruto do método indutivo, pois não se pode observar todos os enunciados singulares. O critério de demarcação apresentado por Popper não ambicionava resolver o problema da significação,

[...] era antes o problema de traçar uma linha (tão clara quanto possível) entre os enunciado, ou sistemas de enunciados, das ciências empíricas, e todos os outros enunciados - quer sejam de caráter religioso, metafísico, ou simplesmente pseudo científico.20

A substituição da verificação pela falsificação é a solução encontrada por Popper para o problema da indução. Essa substituição corresponde, acima de tudo, assumir uma posição critica na ciência, e é isso que garante a sua racionalidade.

O novo critério de demarcação que surge com Popperh é fruto da tentativa de reconstruir o método da ciência de forma que somente a lógica dedutiva seja suficiente para avaliar as proposições científicas. Por acreditar no progresso da ciência, o filósofo defende que todo conhecimento é falível e passível de correções, e deve, portanto, ser duramente criticado. Para Popper, todas as leis e teorias são conjecturas ou hipóteses, não há nada firme e sólido na ciência. O método de ensaio e erro proposto pelo filósofo pretende eliminar falsas teorias por meio de enunciados de observação, e isso se justifica pela "relação puramente lógica de dedutibilidade que nos permite afirmar a falsidade de enunciados universais, se aceitarmos a verdade de enunciados singulares". ${ }^{21}$ 


\section{CONSIDERAÇÕES FINAIS}

Desta forma, podemos concluir que o método da ciência deixa de estar relacionado com as confirmações definitivas e acabadas das teorias. Para Popper, a ciência possui um caráter falível e está sempre sujeita a erros, suas teorias não são mais leis universais aceitas como dogmas, o saber científico é hipotético e provisório, mas ainda assim é a mais confiável forma de saber.

O falsificacionismo, de acordo com Popper, elimina o problema da indução uma vez que o seu método, ao confrontar as leis e teorias científicas com a experiência, permite estabelecer a falsidade delas justificadamente, pois tem a capacidade de fornecer a base lógica necessária para eliminá-la, ou, numa segunda opção, para escolher a melhor dentre teorias concorrentes, mesmo não podendo afirmar, nestes dois casos, que as teorias sejam definitivamente verdadeiras, mas que são aceitas provisoriamente.

\section{NOTAS}

${ }^{1}$ Licenciada em filosofia pela Universidade Estadual de Santa Cruz - UESC. Especialização em andamento pela Universidade Estadual de Santa Cruz UESC. juliana-b@hotmail.com

${ }^{2}$ POPPER, 2006, p. 282.

${ }^{3}$ POPPER, 2006, p. 67.

${ }^{4} \mathrm{O}$ clássico exemplo indutivista que afirma que "o sol nascerá e por-se-á uma vez em 24 horas" baseado na observação do nascer do sol diariamente, foi refutado com a constatação de um fenômeno natural que ocorre nos Círculos Polares, onde no inverno há dias sem sol, um fenômeno conhecido como noite polar.

${ }^{5}$ POPPER, 1975, p. 16. 
${ }^{6}$ POPPER, 2006, p. 67.

${ }^{7}$ POPPER, 1975, p. 16.

${ }^{8}$ POPPER, 1977, p. 94.

${ }^{9}$ POPPER, 2007, p. 28.

${ }^{10}$ POPPER, 2007, p. 36.

${ }^{11}$ POPPER, 2006, p. 62.

${ }^{12}$ POPPER, 2007, p 37.

${ }^{13}$ PINTO, 1998, p 3.

${ }^{14}$ WITTGENSTEIN, 1968: 1.1.

${ }^{15}$ WITTGENSTEIN, 1968, 1.12.

${ }^{16}$ OLIVEIRA, 1996, p. 98.

${ }^{17}$ WITTGENSTEIN, 1968, 2.17.

${ }^{18}$ OLIVEIRA,1996, p. 105.

${ }^{19}$ POPPER, 2006, p. 263.

${ }^{20}$ POPPER, 2006, p. 62-63.

${ }^{21}$ POPPER, 2006, p. 85.

\section{REFERÊNCIAS}

OLIVEIRA, M. A. Reviravolta lingüístico-pragmática na filosofia contemporânea. São Paulo, SP: Loyola, 1996.

PELUSO, Luis Alberto. . A filosofia de Karl Popper: epistemologia e racionalismo crítico. Campinas: Papirus, 1995.

PINTO, P. R. Margutti. Iniciação ao silêncio: análise do Tractatus de Wittgenstein. São Paulo: Edições Loyola, 1998.

POPPER, Karl. A Lógica da pesquisa científica. Tradução: Leonidas Hegenberg e Octanny da Mota.São Paulo: Editora Cultrix, 2007. 
POPPER, Karl. Autobiografia intelectual. Tradução de Leônidas Hegenberg; Octanny Silveira da Mota. São Paulo; Cultrix; EDUSP, 1977.

POPPER, Karl. Conhecimento objetivo. Belo Horizonte, Itatiaia. 1975

POPPER, Karl. Conjecturas e Refutações. Tradução: Benedita Bettencourt. Coimbra: Editora Almedina, 2006.

VALLE, Bortolo. Introdução ao pensamento de Karl Popper. Bortolo Valle, Paulo Eduardo de Oliveira. Curitiba: Champagnat, 2010.

WITTGENSTEIN, L. Tractatus logico-philosophicus. São Paulo: Ed. Nacional, 1968. 